\title{
Evolution of Life Forms in Our Universe
}

\author{
Robert M. L. Baker Jr.' ${ }^{1}$ Bonnie Sue Baker ${ }^{2}$, Jeannie Hall Moller Fontana1 \\ ${ }^{1}$ Gravwave LLC, Palm Desert, USA \\ ${ }^{2}$ Transportation Sciences Corporation, Palm Desert, USA \\ Email: drrobertbakerjr@gmail.com, bonniesuebaker@gmail.com, jeanniefontanamd@gmail.com
}

How to cite this paper: Baker Jr., R.M.L., Baker, B.S. and Fontana, J.H.M. (2021) Evolution of Life Forms in Our Universe. Journal of Modern Physics, 12, 1975-2002. https://doi.org/10.4236/jmp.2021.1214114

Received: November 11, 2021

Accepted: December 24, 2021

Published: December 27, 2021

Copyright $\odot 2021$ by author(s) and Scientific Research Publishing Inc. This work is licensed under the Creative Commons Attribution International License (CC BY 4.0).

http://creativecommons.org/licenses/by/4.0/

\begin{abstract}
Paraphrasing Descartes: A Life form entity "thinks" therefore it exists. Our research method is to take evolution to be change or adjustment in order for the entity to "survive." Such evolutionary "adjustments" are expected to occur after the Life form entity has evolved into a thinking "cyborg" or "humanoid" Life form. That is a life forms whose intellectual and physical capabilities are extended beyond normal by a combination electronic, organic and mechanical means. Ultimately an Accelerated Evolutionary adjustment is expected to be to be accomplished by a physical modification of "cyborg" or "humanoid" Life form entities by themselves or by other such entities. Here we define a humanoid as a cyborg self-controlled by an electronic artificial brain that has "freewill". The major law for all life forms resident in our Universe be they amoebas, fungus, bugs, or bunnies, human or non-human humanoids is survival of the fittest. We speculate that humans are not the only life form that has been, is, or will be present in our Universe-but due to the necessity of survival, no matter how they started out, inevitably their most probable destiny is to wind up as spheres of living-thinking, mental material orbiting a star or galaxy. The most fit life forms require the most effective protection or shield against "predators" ranging from viruses, bacteria, parasites, dangerous life forms, etc. essentially protection or shield against ANY adversarial or dangerous life form or environmental danger such as radiation. The effectiveness of such a shield is directly proportional to their resistivity to predators and other dangers and inversely proportional to their area; the smaller the predator's "target" the better. In the future such Life form entities may be "built not born" or adjusted by other entities. It is proposed that manipulative appendages such as human limbs e.g., arms, legs, hands, etc. will disappear and possibly evolve into "mind-controlled" or "thinking-controlled", artificial-intelligence implemented external mechanisms and devices. How would life forms evolve to maximize volume, required to house their increased mental capabilities consisting of cognitive/microelectronic material of the highest possible density, and minimize surface area for protection? Since
\end{abstract}


the sphere is the geometric figure exhibiting the largest volume to area ratio, their shape would be spherical. Life forms could, therefore, evolve into spherical "artificial" planets orbiting stars or galaxies-powered by "starlight". We will not, however, consider directly the incorporation of multiple Life forms in the same sphere. Science fiction is utilized only to illustrate concepts.

\section{Keywords}

Evolution, Cyborg, Humanoid, Brain Communication, Life Form, Cosmology, Magnetic Nanoparticles

\section{Introduction}

This paper investigates the evolution of life forms in our Universe. Paraphrasing Descartes: A Life forms entity "thinks" therefore it exists. We take evolution to be change or adjustment in order for the entity to "survive." Such evolutionary "adjustments" are expected to occur after the Life form entity has evolved into a thinking "cyborg" or "humanoid" Life form. A humanoid is a cyborg self-controlled by an electronic artificial brain that has "free will". That is a life form whose intellectual and physical capabilities are extended beyond normal by a combination electronic, organic and mechanical means. Ultimately an Accelerated Evolutionary adjustment is expected to be to be accomplished by the physical modifications of "cyborg" or "humanoid" Life form entities by themselves or by other such entities. We will greatly reduce our paper's scope to carbon-based chemical activities of the organic animal variety, inclusive of, but not restricted to Homo sapiens. The major law for all life forms resident in our Universe be they amoebas, fungus, bugs, or bunnies, human or non-human humanoids is survival of the fittest. (Or, more generally, life forms more suited to the environment are more likely to survive) as suggested by [1] Charles Darwin (1859), [2] Herbert Spencer (1852) and others. We will utilize Homo sapiens simply as an example to speculate on how life forms will evolve. We speculate that humans are not the only life form that has been, is, or will be present in our Universebut due to the necessity of survival, no matter how they started out, inevitably their most probable destiny is to wind up as spheres of living-thinking, mental material: life forms orbiting around and nourished by radiation from stars and/or galaxies. That is our speculation or model. We are therefore suggesting a "Working Hypothesis", which is defined (Wikipedia) as a hypothesis that is provisionally accepted as a basis for further research in the hope that a tenable theory will be produced, even if the hypothesis ultimately fails or is significantly modified (Isaac Newton's Principia Mathematica, as significantly modified by Einstein, is an example). It is essentially an encouragement for further research.

The more fit life forms require the most effective protection or shield against "predators" ranging from viruses, bacteria, parasites, dangerous other life forms... essentially protection or shield against ANY adversarial or dangerous life form 
or environmental danger such as harmful radiation. The effectiveness of such a shield is directly proportional to their resistance to predators and other dangers, such as harmful radiation, and inversely proportional to their area. That is, the smaller their exposed area, the smaller a target they present to any and all predators and dangers such as radiation. Resistance of the shield will be determined by the characteristics of the predators or environmental dangers encountered and for this study is not considered to be a major issue. For example, their shield may be variable in absorption from near black body (for absorption of radiant energy to power them) to high reflectivity of harmful radiation, particles, or projectiles, etc.

The most fit life form will have maximized imagination ${ }^{1}$. Maximum imagination is functionally defined as the entity who can best define imagination. A circular definition or argument of course somewhat similar to the circular orbit of the entity around a star or galaxy. In this regard. Science Fiction is utilized to illustrate concepts, especially in section 4.

Whether or not Life form civilizations will winnow down to one or a few is another issue not directly addressed herein. It may well be that ultimately life forms congregate into subgroup civilizations in order to implement and foster collective activities. Friendship with other life forms, which is involved in the formation of subgroup civilizations and on the winnowing down of Life form civilization's number, may be a thing that affects a life form's psychological and or physical health and wellbeing. Friendship is extremely complex-in fact, too complex to analyze properly. For example, the demands that maintaining a life form's relationships with other life forms makes on the brain's computing power is so great that the number of friends Homo sapien life forms can have at any one time might currently be, very roughly limited to around 150 . British evolutionary anthropologist Robin Dunbar (who works at the University of Oxford) in Malcolm Gladwell's Book, The Tipping Point, stated that there are different layers of friendship or fellowship, depending on how close you are with someone, which is impossible to analyze in great detail. We will, therefore, not analyze directly the incorporation of multiple Life forms in the same sphere.

As mentioned in the Introduction, all life forms are expected to become electronic, organic or mechanism-enhanced or "cyborgs" or "humanoids" and in the future we may be "built not born" or adjusted or modified by other entities. It is proposed in Section 1 that manipulative appendages such as human limbs e.g., arms, legs, hands, etc., after thousands or millions of years of non-use, will disappear and evolve into "mind-controlled" or "thinking-controlled", artificialintelligence-implemented external mechanisms and devices. An example is shown ${ }^{1}$ Albert Einstein is reported to have stated: "Imagination is more important than knowledge. For
knowledge is limited to all we now know and understand, while imagination embraces the entire
world, and all there ever will be to know and understand." The most FIT life form will have max-
imized imagination. Maximum imagination is functionally defined as the entity who can best define
imagination. A circular definition or argument of course, but possibly somewhat similar, imagina-
tively, to the circular orbit of a Life form entity around a star or galaxy. In any event, the more fit life
form will have a large amount of knowledge and be "quick thinking", but even more importantly
exhibit the most imagination. 
in Figure 1 and Figure 2, in which an artificial arm and hand take control of an external device.

Figure 2, first-ever successful mind-controlled robotic arm without brain implants in 2019, using novel sensing and machine learning techniques, Bin $\mathrm{He}$ and his lab (He, B. 2020) have been able to access signals deep within the brain, achieving a high resolution of control over a robotic arm.

https://www.youtube.com/watch?v=UkZquERzoOo.

All such controls and communications will be by mind and between similar life forms mind to mind. Such controls and communications are not anticipated to involve significant external systems such as antennas, but only devices "internal" to a given life form. How would life forms evolve to maximize volume, required to house their increased mental capabilities consisting of cognitive/electronic material of the highest possible density, and minimize surface area for protection-that is be a smaller target for predators? Since, as previously mentioned, the sphere is the geometric figure exhibiting the largest volume to area ratio, their shape would be spherical. Please see Figure 3 for a science-fiction picture of such a life form.

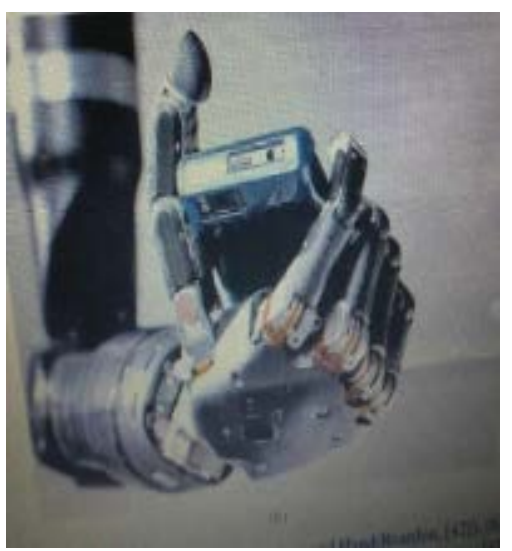

Figure 1. An artificial arm and hand take control of an external device. From Figure 2 of [3] Baker and Baker (2016).

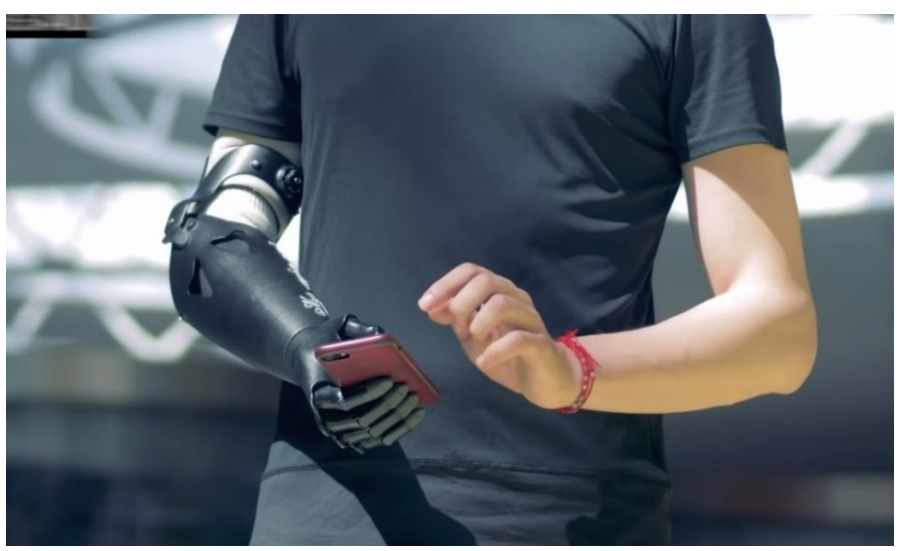

Figure 2. Breakthrough in non-invasive mind-control of robotic limbs ([4] He, B., 2020). 


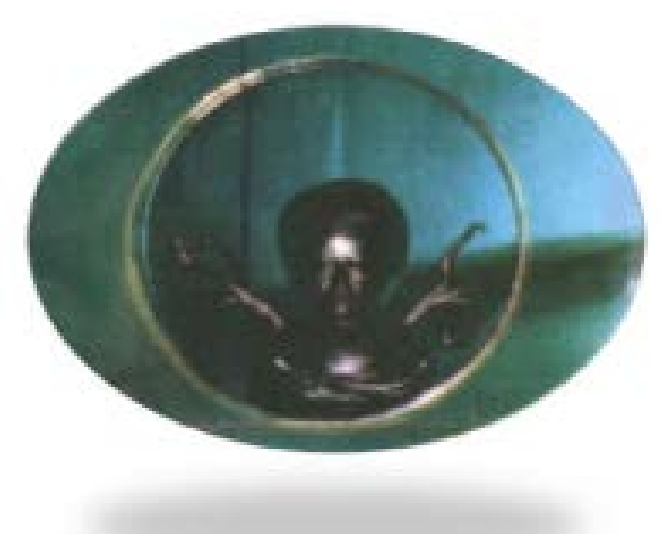

Figure 3. Fictional picture of a spherical life form the 1953 Science-Fiction Movie "Invaders from Mars."

We believe that life forms will evolve into spheres composed of living mental material whose size will be determined by their density needed to properly function, environment, and the local gravitational field. That is, the sphere's mass will need to allow necessary movement and be "sustainable" in the sphere's local gravitational field. For their sustenance or energy, Life forms would, therefore, evolve into spherical "artificial" planets composed of high-density living mental material orbiting stars or galaxies—nourished and powered by "starlight." Their inter-Life form and inter-stellar communications, to be discussed in Section 2.5, would be by means of mind-controlled and brain activated transceivers of high-frequency gravitational waves (HFGWs). As discussed in the footnote 1, the most fit life forms are expected to have maximized imagination.

\section{Amazing Trends in Life form Evolution}

\subsection{The Rise of the Cyborg and the Humanoid Spheres}

We agree with J. A. Hodgson (as quoted by [5] L. Jones (2021)): "We don't know, but, certainly, human genetic variation is increasing. Worldwide there are roughly two new mutations for every one of the 3.5 billion base pairs in the human genome every year..." says Hodgson. "...which is pretty amazing-and makes it unlikely we will look the same in a million years." We are speculating that the engine of change or adjustment of a life form is adaptation to a (final) form that survives. We believe we can conjecture intelligently on the evolutionary path that survival brings life forms on in our Universe. Notice that we are considering any "life form" not necessarily a specific life form. But one of the primary premises of our conjecture is that "All roads lead to Rome". That is independent of their initial condition, all surviving humanoid life forms in our Universe will eventually reach the same spherical final life form on stellar orbit given about stars or galaxies in a sufficient length of time, such as many billions of years (possibly hundreds of billions of years as will be mentioned in Section 4). Because it is such an amazing and dramatic anatomical change predicted for life forms after their reconfiguration to humanoids, we have and will continue to emphasize (perhaps over emphasize) the eventual change from limbed creatures 
to a spherical form quite frequently,

As was mentioned in [3] Baker and Baker (2016) “...advance has been taking shape over the past several millennia, but most dramatically over the last few decades. Broadly speaking this amazing advance is the introduction of electronic components into the human body and especially into the brain." As a specific example of such advancement is the actual mind control of a mechanical hand shown in Figure 4. Here we see an actual Homo sapien life form whose mind, via an electronic interface, controls a mechanical hand to feed herself a candy bar and can feel the bar via haptic feedback ${ }^{2}$ !

Prosthetic in Figure 5 enables a wide range of daily activities, such as zipping a suitcase, shaking hands, and petting a cat ${ }^{2}$.

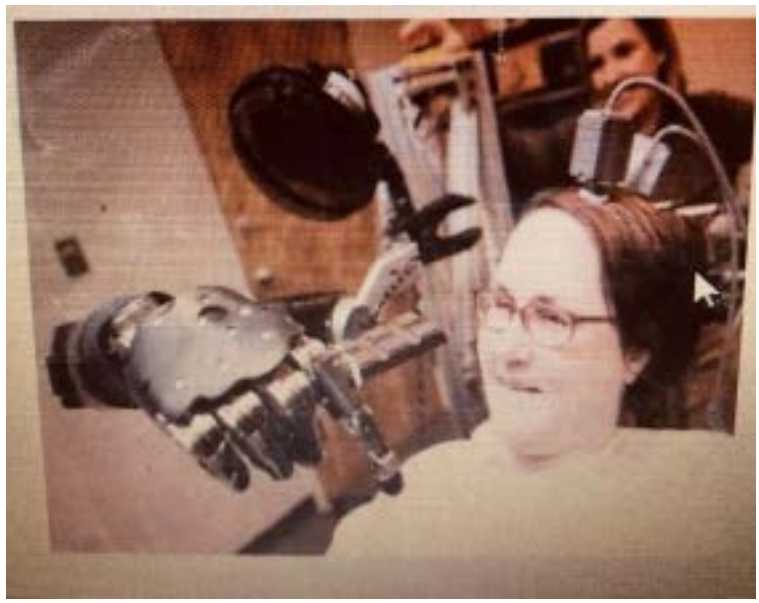

Figure 4. An actual Homo sapien person whose mind, via an electronic interface, controls a mechanical hand to feed herself a candy bar. From Figure 2 of [3] Baker and Baker (2016).

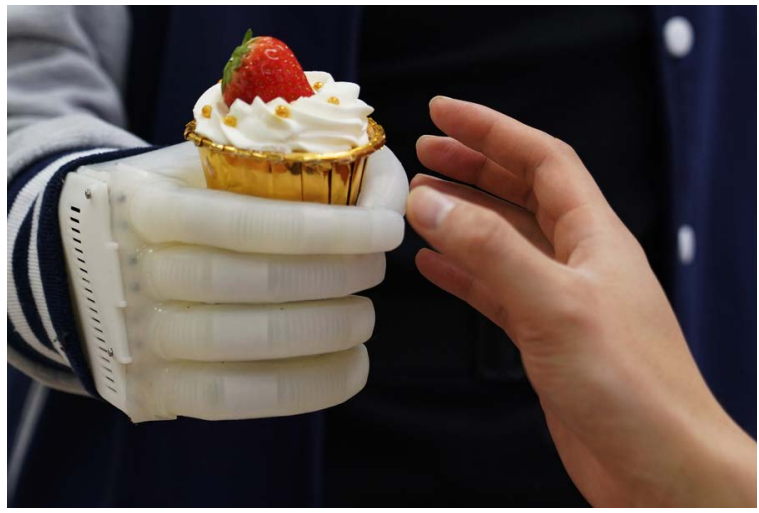

Figure 5. Inflatable robotic hand gives amputees real-time tactile control. Please see:

https://www.itproportal.com/features/future-of-artificial-i ntelligence-for-2020.

${ }^{2}$ Haptic feedback is the use of touch to communicate with users. Most people know the feeling of a vibration in a mobile phone or the rumble in a game controller-but haptic feedback is much more than that. [32] (Robert Blenkinsopp, 2020). 
As pictured in Figure 6, $\mathrm{Ai}-\mathrm{Da}$ is the world's first ultra-realistic artist robot powered by AI and named after Ada Lovelace, the first female computer programmer in the World. She is a humanoid with human facial features and a robotic body created by the Oxfordians, a group of cutting-edge art and technology experts formed in 2020. Please see: https://en.wikipedia.org/wiki/Ai-Da.

In the near future, the clear outcome would be for Homo sapien and, in general ALL "advancing" Life forms in our Universe, eventually to evolve into a combination cybernetic or electronic and biological being: a "cyborg" or even to a "humanoid", a cyborg controlled internally by an organic brain as shown in Figure 6, Figure 7. As the Life form cyborg "controllers" begin to control their ever improving (evolving) cyborg "helpers", the difference between them begins to narrow, a distinction without a difference: For example, the "transformation" or "mental implants" in the mouse brain [6] Vetere G., Tran L. M., Moberg S., et al. (2019) and, as will also be mentioned, tagging neurons, the mind-to-mind communication of Figure 8 and the prosthetics examples, of Figure 1 and Figure 5 will essentially join the controller and the associated "cyborg" functions.

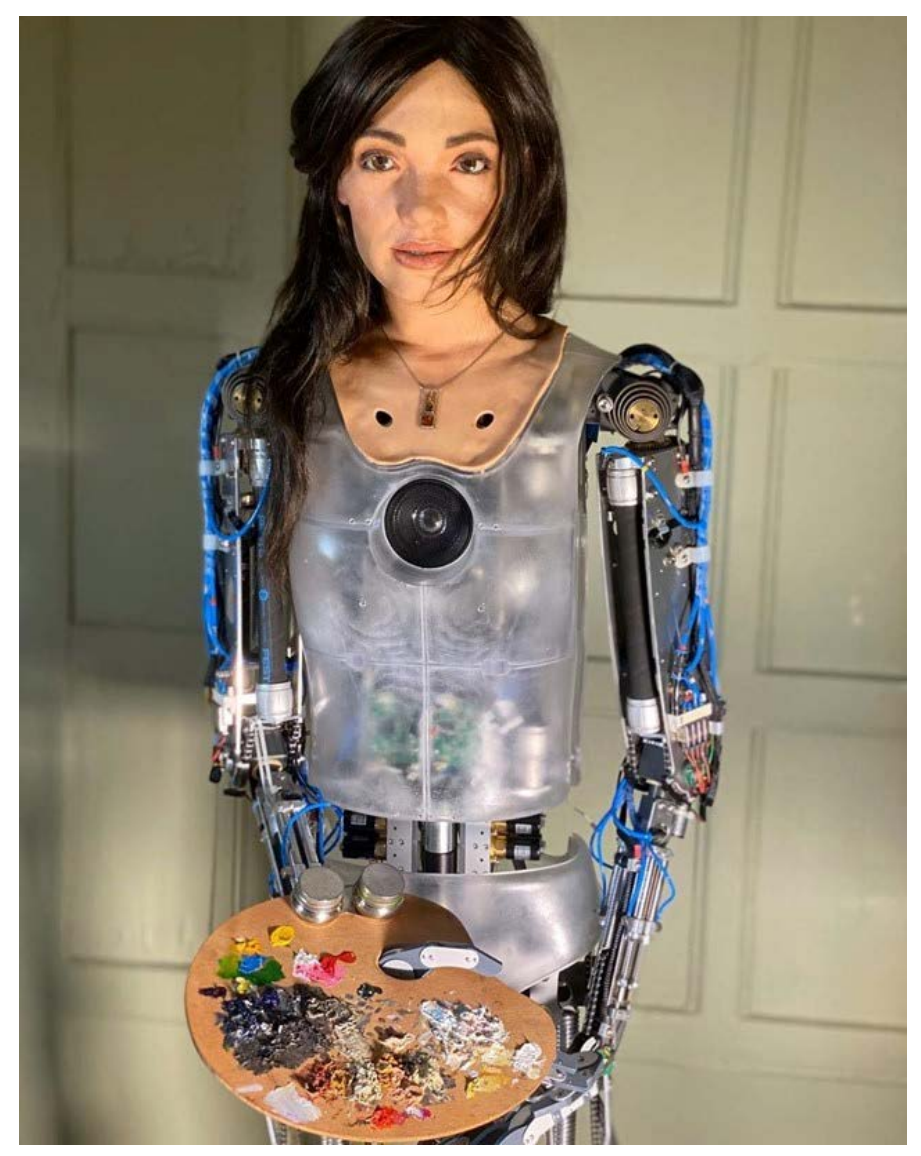

Figure 6. "Hello, Baker's residence. They are unavailable right now. Please leave your name and number. I am the Baker's Cyborg, AiDa, Robot/ Humanoid ID number 823. If you are a Cyborg, please leave your Humanoid ID number and maybe we can get together sometime." 


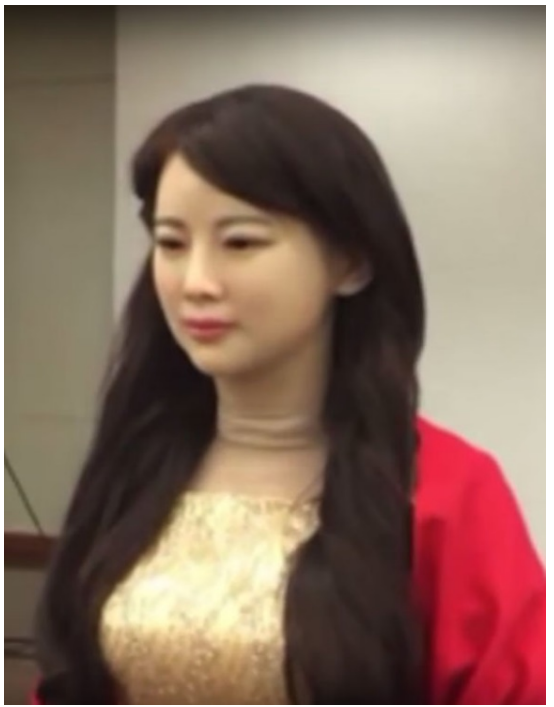

(a)

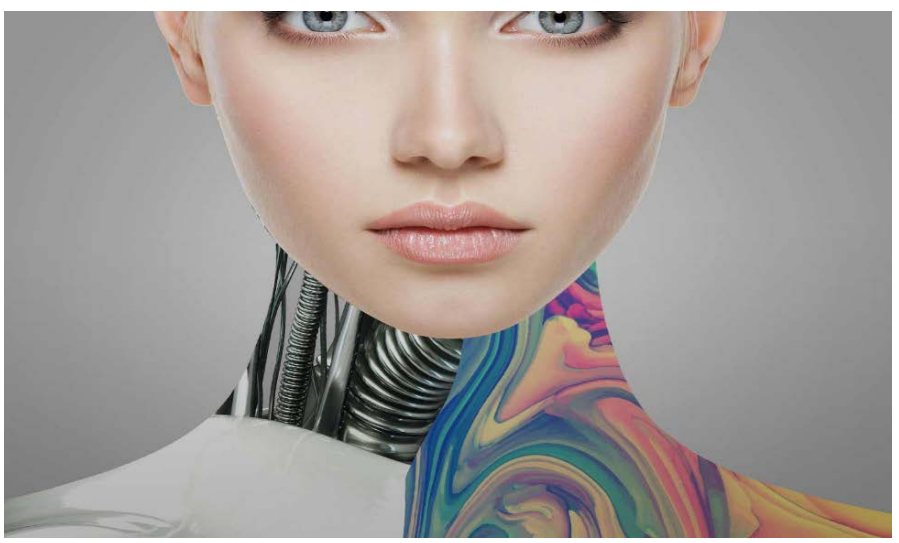

(b)

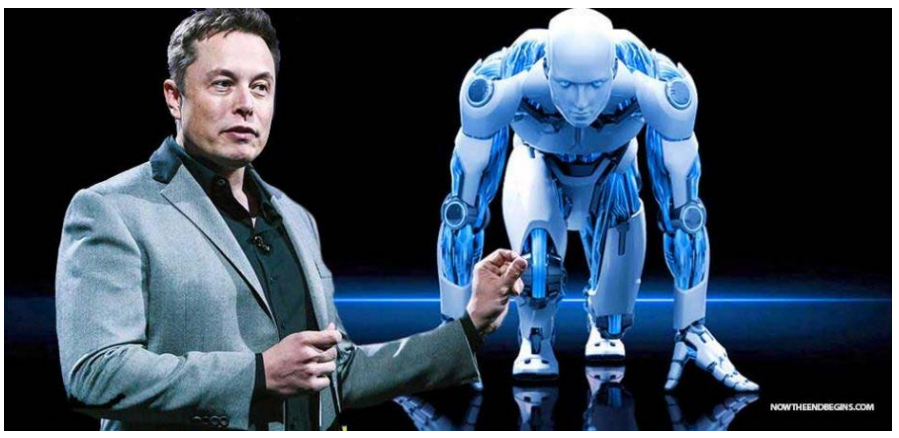

(c)

Figure 7. (a) This is the near present-day cyborg, showing the development of machine learning: An AI cyborg. Eventually, more advanced cyborgs may evolve into (b); (b) This is one outcome of the evolution of cyborgs-human features and personality traits programed by a machine learning AI cyborg or humanoid. It is to be completely renovated and evolved to someone like the fictional spherical humanoid in Figure 3; (c) Elon Musk predicts Artificial Intelligence will be better than humans at everything, including sports, in the year 2030. 


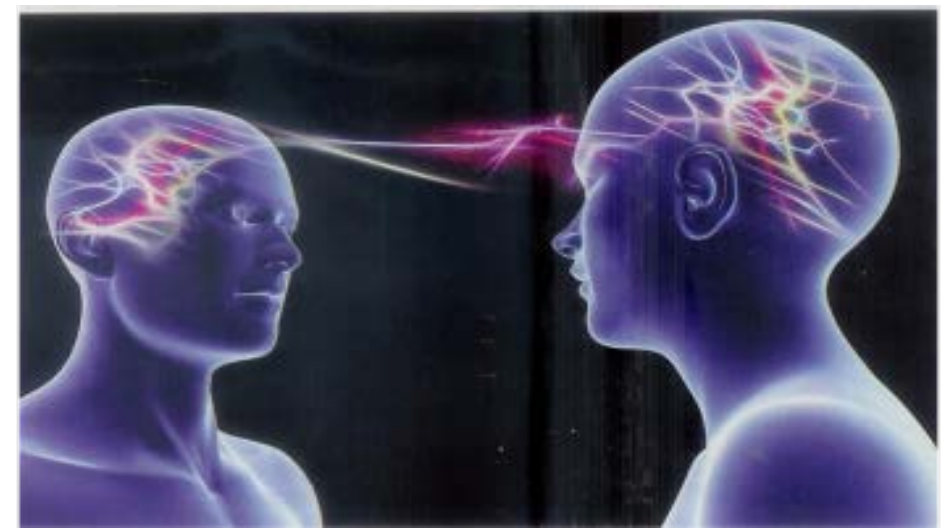

Figure 8. Brain-to-brain direct communication [20] (Power (2014) and [21] Grey (2016)). Mind Melds and Brain Beams: The Dawn of Brainto-Brain Communication (https://www.youtube.com/watch?v=SObhSqYglvQ).

Robert F. Service (2013) [7] said in the Journal SCIENCE"The beginnings of a cyborg world have already arrived...!” and [8] Manuela Veloso who suggests that we "Embrace a robot-human world" (2015). It is suggested that such cyborg forms of intelligent beings would allow advanced civilizations to endure at least hundreds of thousands of years. In the future, [9] Greene (2017) said, there is a good possibility that humans will find a way to merge with their machines: "We're already finding, on much shorter timescales, [that the] distinction between biological beings and artificial beings is starting to blur," Greene said. "I could see a new kind of hybrid species out of the biological and the synthetic."

What if also an Artificial Memory could be implanted in your or a humanoid's brain? Just imagine an Artificial Education-your brain filled with Artificial Knowledge! Experiments reported by [6] Vetere G., Tran L. M., Moberg S., et al. (2019) indicate “...we created a fully artificial memory in mice. Similarly to a natural memory...” More recently a Boston College team [10] (Denny, 2020) modified mice's brains with light-sensitive proteins from algae DNA. Denny's team can tag neurons that encode individual memories with glowing molecules. This enables them to see, under a microscope, which cells were active when a mouse learned something, and which cells were active when it remembered something. In addition, once they've labeled a memory neuron or neurons, they can switch it off and on with a laser using a technique called optogenetics. This Artificial Education is somewhat like taking Soma in the book Brave New World to "go" on vacation, while laying down in bed in your home: creates memories of a vacation for you.

However, "Naked Knowledge" may not be as important as we might first think. Naked knowledge of paints, canvases, art history, etc. would not an artist make! Artificial simulation of abstract thinking would probably be extremely difficult to implant in memories as well as muscle-control protocols for physical action, e.g., sports and emotions like love, feelings and hate or dislike. Perhaps these mental functions are involved in other parts of the brain not analyzed like 
the basolateral amygdala portion observed in the just referenced study. Although implanted in memory hypnotically, the fictional conditioned response of the soldiers in the movie "Manchurian Candidate" (1962) was "Raymond Shaw is the kindest, bravest, warmest, most wonderful human being I've ever known in my life" according to the story they all still did not like him! Also suggested by Frank J. Tipler (http://www.franktipler.com/) in 1994. So, BEWARE: one must take extreme care about whose rendition of history or any other "facts" is being implanted in your or any life form's brain ${ }^{3}$.

\subsection{Artificial, Accelerated Evolution}

One probable evolving Life form (e.g., cyborg or humanoid) would involve the replacement or repair of their "parts" especially if they were largely composed of electronic components as we predict for human life forms in the future. Such cyborgs and humanoids would be essentially immortal or at least very long-lived until they are replaced or significantly repaired.

An almost obvious development would be "Life form Evolution" that is, replacement parts could also be the installation of improved or upgraded parts-in fact, complete change or adjustment of the design of all future "models" of one "line" of humanoids. Such adjustment amounts to Accelerated Evolution and humanoids building humanoids. We now embark on the treacherous trail of considering "judgment", "consciousness", "personality", "freewill," etc. in order to predict humanoid evolution. Again, we invoke our paraphrase of Descartes: "A Life form entity 'thinks' therefore it exists." Thus the design of the most survivable humanoid entity boils down to the definition of "thinks." And that boils down to imagination ("knowledge" is just an implant in an organic or electronic-brain part of a humanoid entity). So, EVOLUTION is by survival of the Life form entity or entities having the BEST IMAGINATION. Therefore, we leave it to you, dear reader, to suggest what Life form entity would have the best imagination leading to its survival and we make a full circle. Figuratively speaking, that circle is the orbit about our star.

\subsection{The Specific Steps of Life form Evolution}

The following compact summaries of the evolutionary steps of life forms in our Universe, specifically humanoids, are all based on survival of the fittest.

1) When all operations of life forms, such as locomotion and control of devices as shown in Figure 1, Figure 2, Figure 4 and Figure 5, are accomplished by mindcontrol, perhaps in a few hundred or millions of years, the fit Life form entities will eliminate their hands, arms and legs as completely unessential encumbrances.

2) The most efficient manner in which needed energy can be collected and delivered to a humanoid will be to place the humanoid or humanoid civilization on orbit, artificial planets about a long-lasting stellar energy source. The radiant ${ }^{3}$ Naked Knowledge speaks to the importance of the Turing Test: a machine can still, to this day in 2021, not tell you what an orange actually TASTES like unless a human gives it the information to state. 
energy from that energy source would probably be delivered by photovoltaic conversion.

3) The more survivable fit life forms will seek protraction from pernicious predator entities, radiation, micrometeorites, etc. by the humanoids assuming a smaller surface or target area and a higher density internal composition, that is a spherical form composed of very resistant surface material.

Advanced humankind is evolving into a cyborg entity having a complete artificial education. Furthermore, such entities could well be repairable and include technological improvements in their "parts" as time goes by. As mentioned, in a sense cyborgs could be immortal and constantly improving, or evolving. In any event, it is concluded that the Life form entity's lifespan on our Earth will dramatically increase with the advent of advances in evolutionary cyborg and eventually humanoid technology. Obviously, such an advance would produce a myriad of current problems for humanity such as the necessity for stringent population/birth control and other; new governmental-paradigms to manage not only transition to a huge aging population, but possibly an "ageless" population, mentioned in [3] (Baker and Baker (2016)). Indeed, an "ageless" population, could be free of "earthly human needs and desires" and encounter new, yet to be determined, evolutionary pressures.

\subsection{Distinction without a Difference}

As discussed the Life form "controllers" begin to control their ever improving (evolving) cyborg "parts," the difference between them begins to narrow a distinction without a difference: for example, the "transformation" or "mental implants" in the mouse brain [6] Vetere G., Tran L. M., Moberg S., et al. (2019]), the mind-to-mind communication of Figure 8 and the prosthetics examples, of Figure 1 and Figure 5 essentially joining the controller and the associated "cyborg" function to a reasoning or thinking humanoid entity is inevitable. Will life forms in the future be "born or built"? Again, we ask the questions: Will they be "assembled" by putting parts together or being grown together or both? Will Life form entities be eternal in the sense of the reparable survivors being the more "experienced" entities? We have suggested that evolution and survival of the fittest will take their evolving electronic brains to achieve freewill, imagination and become humanoids. Therefore, the answer to the questions is YES.

The research progress is real, as a mix of biologists, materials scientists, and nanotechnology experts are chipping away at a host of challenges. "I see it as building a seamless interface between cells, tissues, and electronics," says Aleksander Noy, a bio-nano-electronics expert at Lawrence Livermore National Laboratory and the University of California, quoted by [7] Service (2013). For now, most of these efforts are focused on providing better health care and quality of life for patients (Figure 4 and Figure 5). Neuro-Engineers at Stanford are using measurements of brain activity to help restore function in people who are para- 
lyzed. Recently, working with a man paralyzed from the neck down, the researchers implanted two arrays of tiny electrodes in a part of his brain responsible for hand movement [11] (Willett, et al. (2021)). As the man imagined writing letters, the scientists used machine learning to translate his brain activity into letters on a screen. Using this system, the man could write 90 letters per minute-more than doubling the previous record for typing via brain activity. The pace of the incorporation of enhancing technologies into "man" is on an exponential growth scale.

Over time, we anticipate devices "...that will make us better athletes and soldiers,” or even reduce our facial wrinkles! For example, the Electrolift ${ }^{\circledR}$ mask device developed and discussed by [12] Baker (2013) "A few years ago these things were science fiction. But now we are seeing the emergence of real devices and applications," stated [13] Noy (2011). "And fast..." says Zhenan Bao, an organic electronics expert at Stanford University in California: "The competition is furious" according to [7] Service (2013). The idea of fusing man and machine has long tantalized humanity. Over the past century, researchers have pioneered myriad efforts to use electronics to measure biological activity and sometimes even alter it. According to Underwood (2013), Geoffrey Ling, a top biotechnology research official at the Defense Advanced Research Project Agency (DARPA), challenged neuroscientists to do something extraordinary: Develop an implantable device in a human brain that can reverse memory loss. Also UCLA's Brain Institute and other universities are developing electronic prostheses that interact with brain regions critical to memory. Victims of stroke may soon have improvement due to brain implants that still allow individual decision making or "thinking" [14] (Ganguly et al. (2015). Michael McAlpine, a mechanical engineer at Princeton University0, and colleagues [15] (Machens, (2012)) reported in the May 1, 2013 issue of Nano Letters [16] (Mannoor (2013)) that they've made the first 3D printed functional organ: a bionic ear that "hears" acoustic sounds and ultrasounds. "We're trying to see if one could introduce augmented functionality that a human wouldn't ordinarily have..." McAlpine says. "Organs from the lab..." appear to be realistic even today as discussed in the June 18, 2015 issue of Nature [17] (Marx, 2015).

\subsection{Communication}

A step in that direction is presented in [18] Hirschberg and Manning (2015). An obvious conclusion is that evolution will produce some form of efficient and unmitigated, yet editable, direct brain-to-brain or mind-to-mind intercommunication (Figure 8). Certainly, the direct "plug" to one brain that transfers thoughts to control a complex prosthetic device, Figure 2, Figures 4-6), could eventually be expected to direct thoughts to and from another brain. In another advance a tiny brain transplant helped a blind teacher see letters again [19] (Chappell (2021)).

The nonprofit Battelle team gets even fancier with their "Brain Storm" nano 
transducers: magnetic nanoparticles wrapped in a piezoelectric shell. The shell can convert electrical signals from neurons into magnetic ones and vice-versa (Figure 9). This allows external transceivers to wirelessly pick up the transformed signals and stimulate the brain through a bidirectional highway. The magnetometers can be delivered into the brain through a nasal spray or other non-invasive methods, and magnetically guided towards targeted brain regions. When no longer needed, they can once again be steered out of the brain and into the bloodstream, where the body can excrete them without harm.

It is essential to identify and quantify the means of their interpersonal intercommunication. A step in that direction is presented in [18] Hirschberg and Manning (2015). An obvious conclusion is that evolution will produce some form of efficient and unmitigated, yet editable (we really do not want all of our: "thoughts" transmuted to others without editing), direct brain-to-brain or mindto-mind intercommunication (Figure 8). Certainly, the direct "plug" to one brain that transfers thoughts to control a complex prosthetic device, (Figure 2, Figures 4-6), could eventually be expected to direct thoughts to and from a brain to another. "By creating a more accessible brain-machine interface that doesn't require surgery to use, DARPA could deliver tools that allow mission commanders to remain meaningfully involved in dynamic operations that unfold at rapid speed," (Figure 10). Al Emondi, DARPA's program manager for Next-Generation Nonsurgical Neurotechnology, said in a statement:

(https://www.bizjournals.com/columbus/news/2019/06/17/battelle-lands-20-4mto-develop-brainstorm-tech.html The shell can convert electrical signals from neurons into magnetic ones and vice-versa. This allows external transceivers to wirelessly pick up the transformed signals and stimulate the brain through a bidirectional highway. The magnetometers can be delivered into the brain through

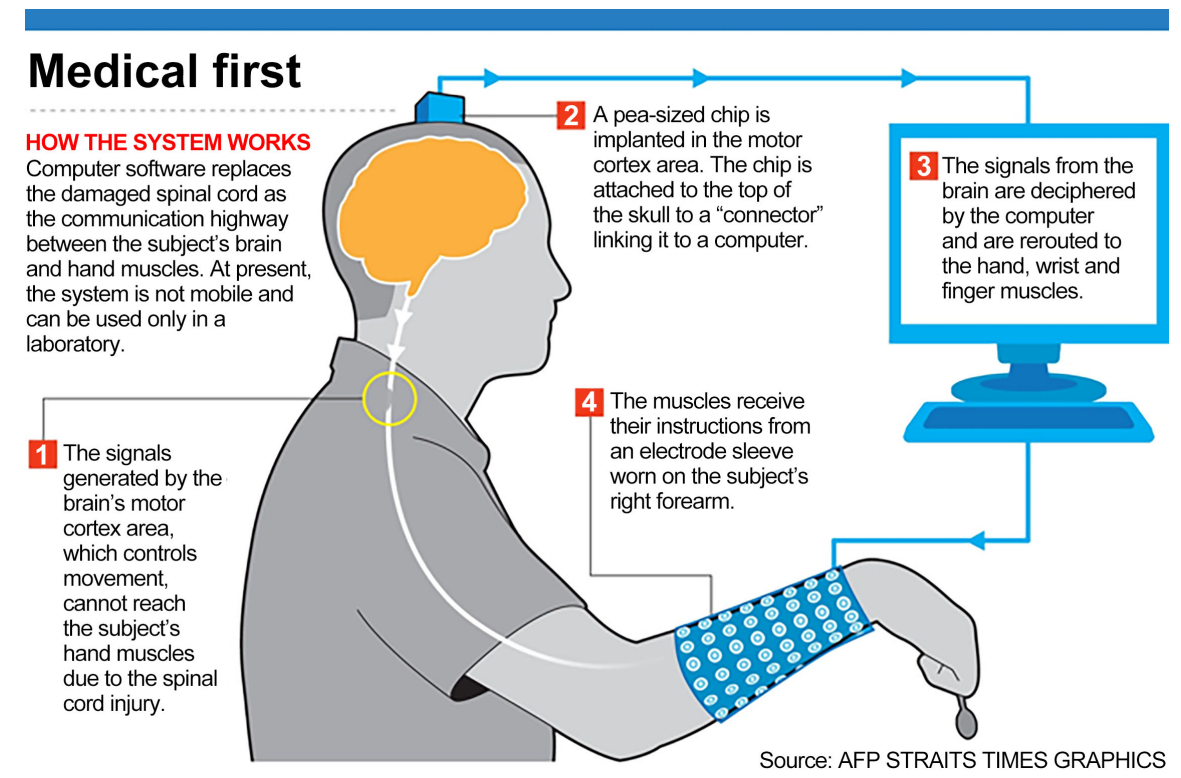

Figure 9. The nonprofit Battelle team gets even fancier with their "Brainstorm" transducers: magnetic nanoparticles wrapped in a piezoelectric shell. 


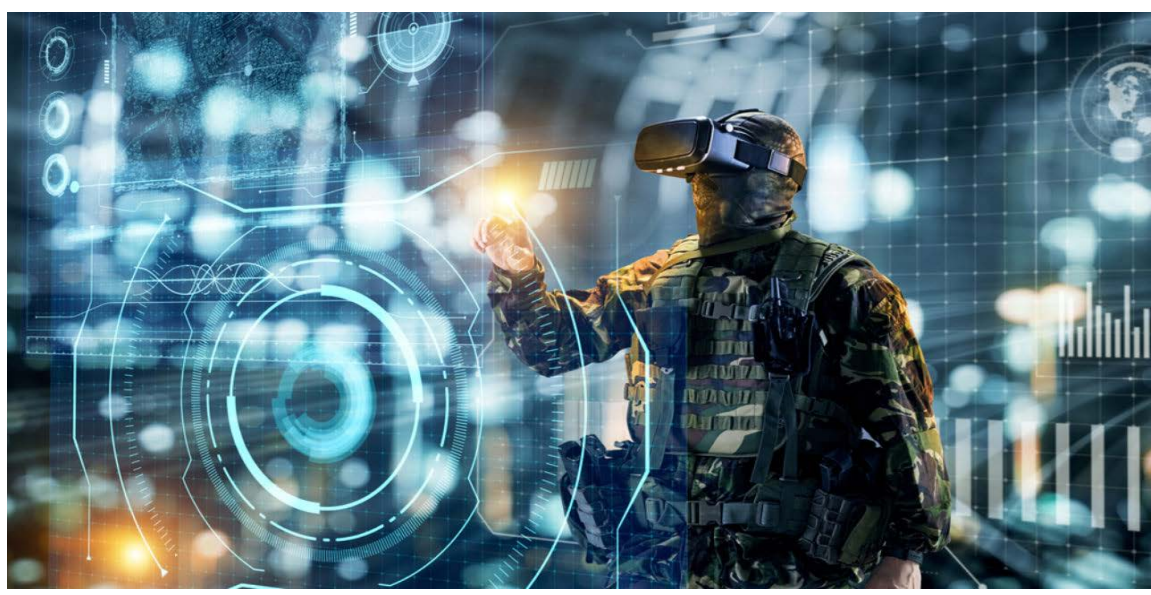

Figure 10. Envisioning the bioengineered soldier of the future through DARPA research programs, Combining DARPA research programs to imagine what super-human capabilities a futuristic soldier could have.

(https://www.bizjournals.com/columbus/news/2019/06/17/battelle-lands-20-4m-to-devel op-brainstorm-tech.html)

a nasal spray or other non-invasive methods, and magnetically guided towards targeted brain regions. Please see Figure 11. When no longer needed, they can once again be steered out of the brain and into the bloodstream, where the body can excrete them without harm.

Gravitational waves would be the most appropriate means of communication to a life form other advanced life forms since they are far-reaching and pass through all matter without attenuation. Such waves would necessarily be of high frequency (unlike the very low frequencies of black-hole merger signals) in order to accommodate the largest information bandwidth. Hence they would be High-Frequency Gravitational Waves or HFGWs.

What is the nature of Gravitational Waves themselves? Please examine the following chart in Figure 12 that compares water waves with gravitational waves. Dicusion of the LiBaker High-Frequency Gravitational Wave (HFGW) Detector or receiver and the HFGW generator or transmitter can be found in [22] Baker (2017) pages 121-122 and 93-112, respectively. Advanced models of such transceivers would support Life form communications in future.

\subsection{Consider the Early Change of Our Homo Sapien Life Form or Species}

According to [23] Haldane (1929) the primitive Earth's atmosphere was essentially reducing, with little or no oxygen. Ultraviolet rays from the Sun induced reactions on a mixture of water, carbon dioxide, and ammonia. Organic substances such as sugars and protein components were synthesized. These molecules "accumulated till the primitive oceans reached the consistency of hot dilute soup." The first reproducing things were created from the Primordial Sea (Figure 13) and then moved from the Hydrosphere to the Lithosphere (Figure 14). 
At some point a primordial organism randomly built the mechanisms needed to replicate its genetic structure, thus really becoming the first life form as in Figure 13. This life form or organism would have had only a single gene. Then

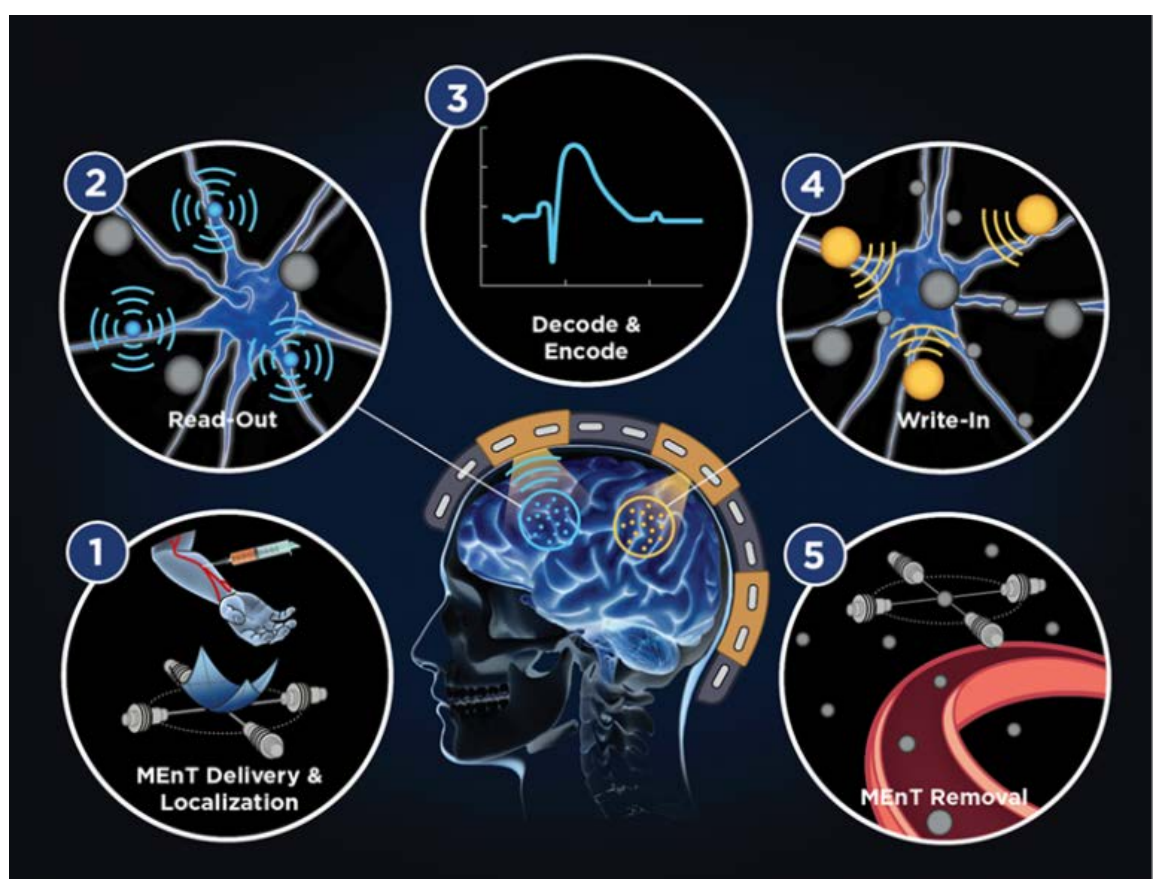

Figure 11. Battelle created this infographic to explain the theory of using magnetic nanoparticles to wirelessly transmit brain signals for outside software to decode.

\section{WHAT ARE GRAVITATIONAL WAVES?}

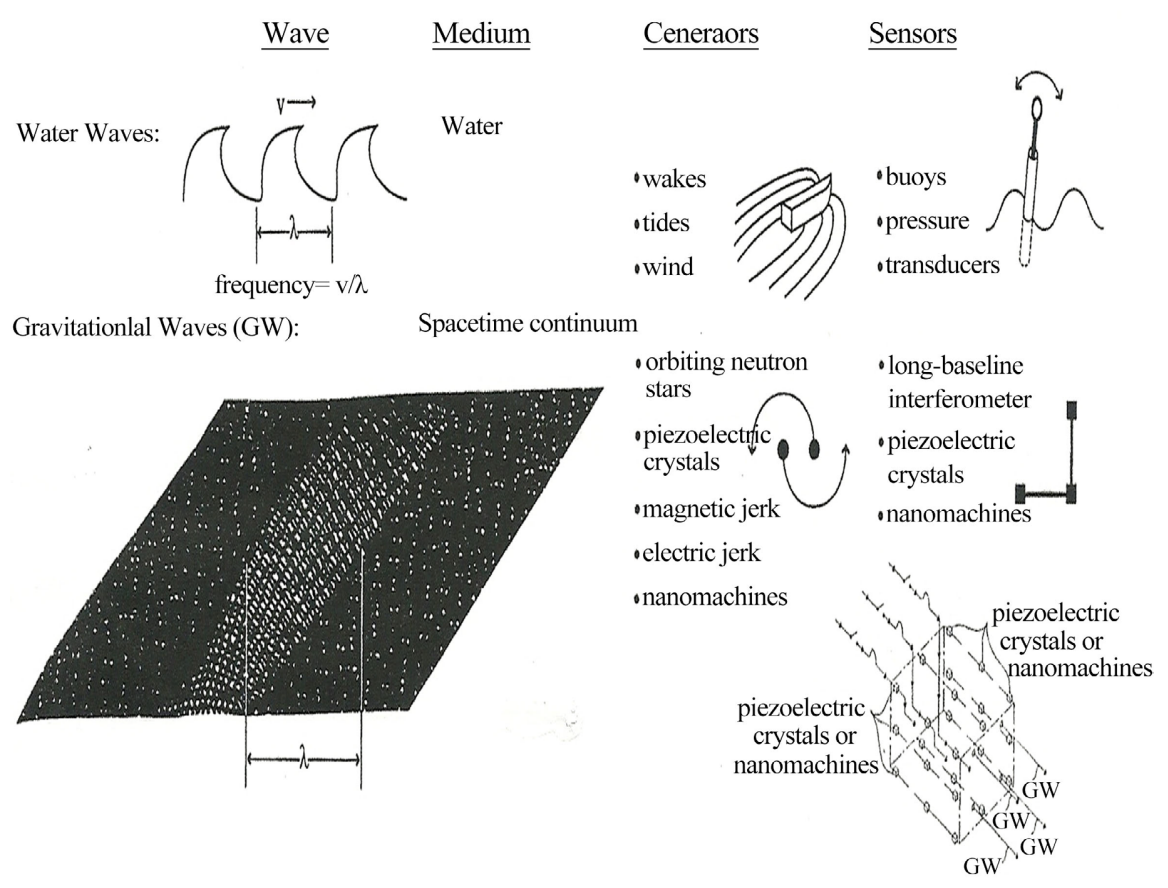

Figure 12. Gravitational waves as described in this diagram are ripples in spacetime, but can be utilized for communications, somewhat like sound or radio waves. 


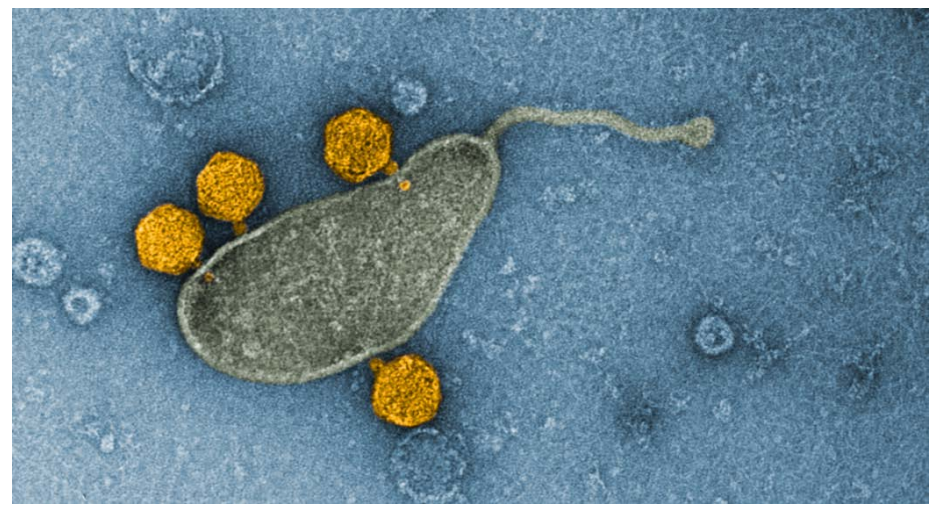

Figure 13. Beginning of life on our Earth in the Primordial Sea. All living beings on the Earth evolved from the "Single Cell" that appeared before the Precambrian Era.

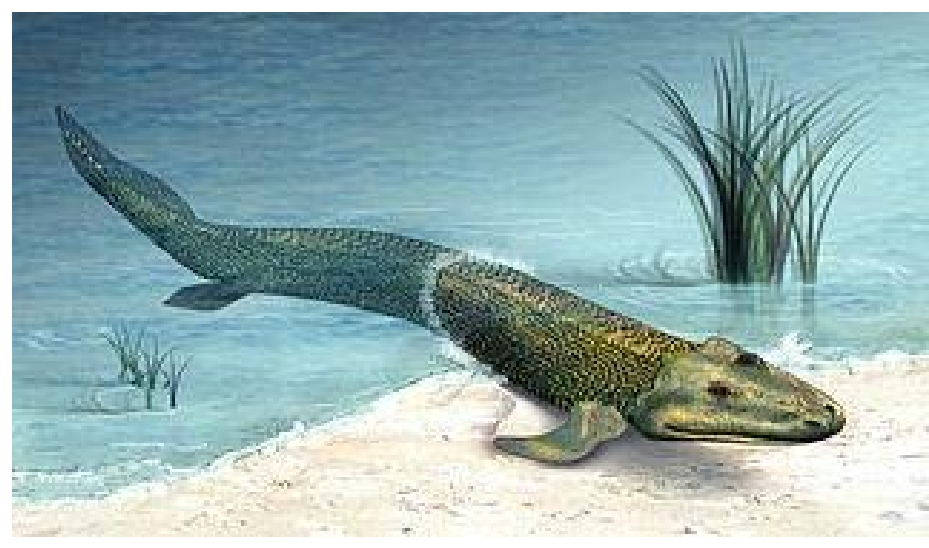

Figure 14. Our Earth's Life form moves from the Hydrosphere to the Lithosphere.

cosmic rays came down and, so to speak, "shuffled the gene deck" and variants appeared to selectively survive and reproduce according to "survival of the fittest" [1] [2] (Spencer, 1852; Darwin, 1859). Next would come our Earth's human Life form's change in the Biosphere as shown in Figure 15. Then human life forms begin to occupy outer space in our Universe as in the space station shown in Figure 16. Such a location would be prophetic of the life form's celestial-orbital, final destination and residence described in Figure 20.

Maybe not be the "Final" frontier for distant-future life forms in a Multiverse (Figure 17). Purely speculative signals "adjacent" Multiverse are discussed in Section 5 of [3] Baker and Baker (2021).

By the way, a quite different approach to the bigger question of the evolution of our Universe itself is given by [24] Vilenchik, L., and Vilenchik, M. (2019) and by [30] Baker (2020) in his "Rollout Theory".

\section{Past Progress and Adjustment Motivated by Survival}

\subsection{Recent Possible Adjustments}

Life forms will need to adjust to any change in their environment in order to 

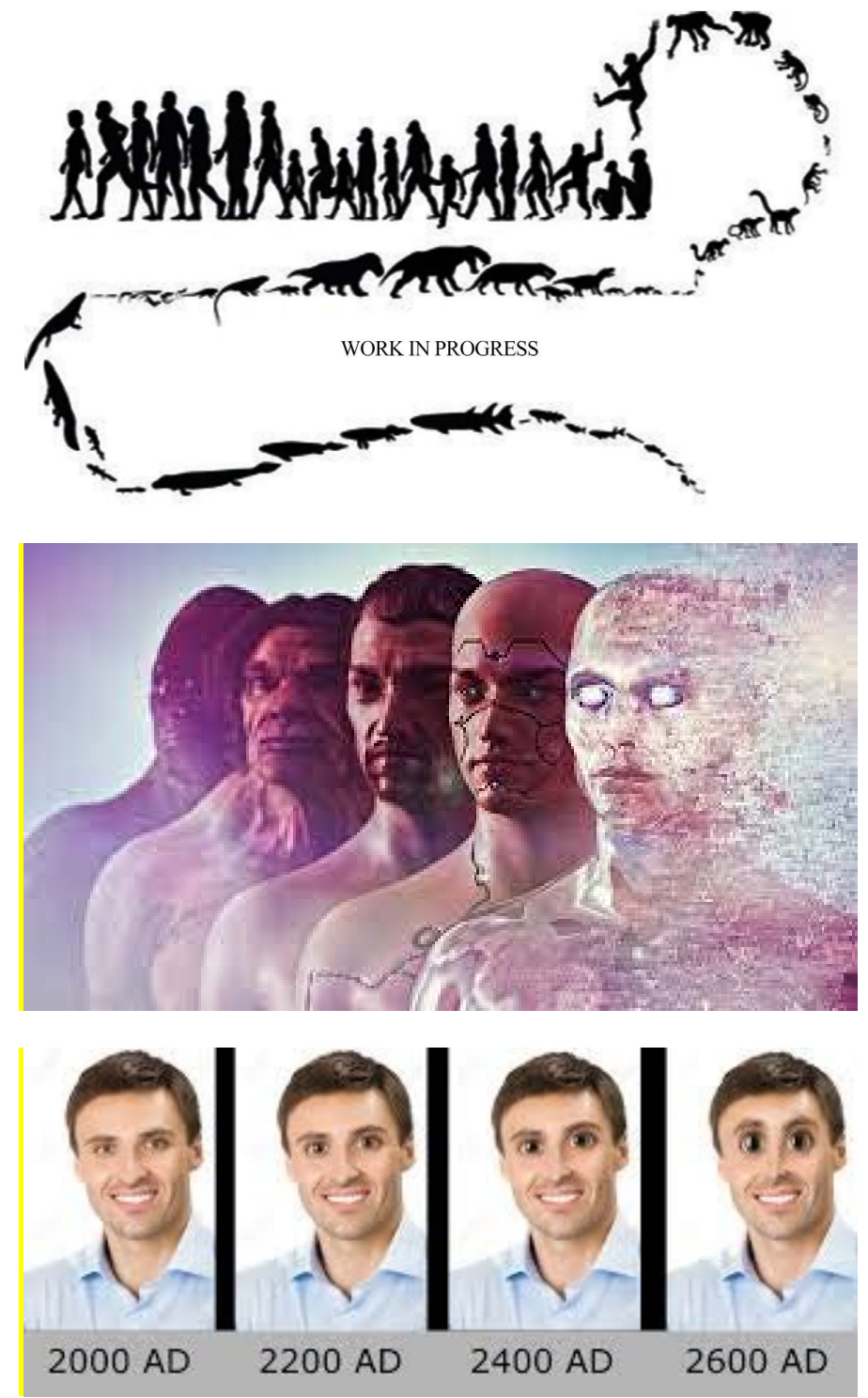

Figure 15. Our Earth's human Life form's change in the Biosphere.

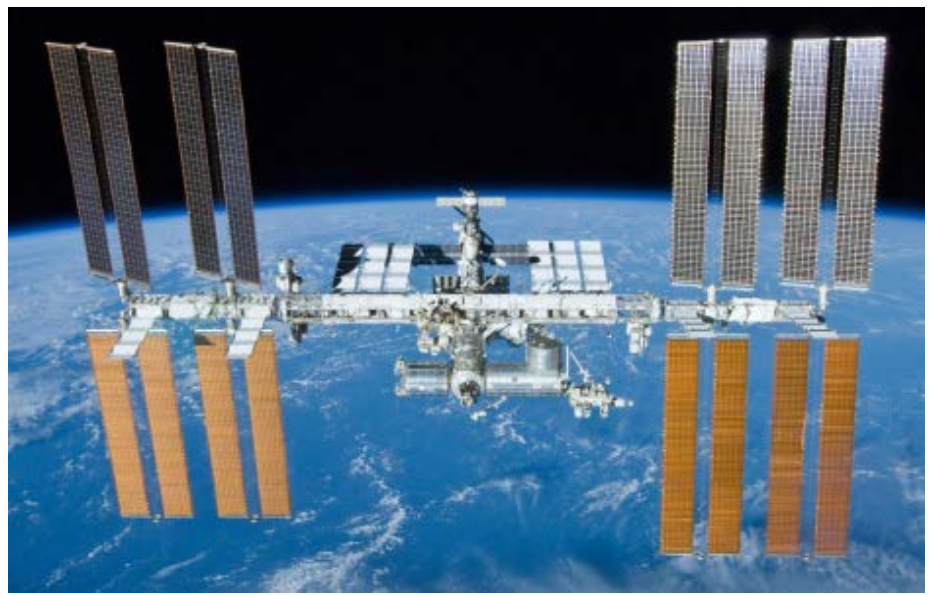

Figure 16. Some of human life forms occupy Outer Space: "The Final Frontier". 


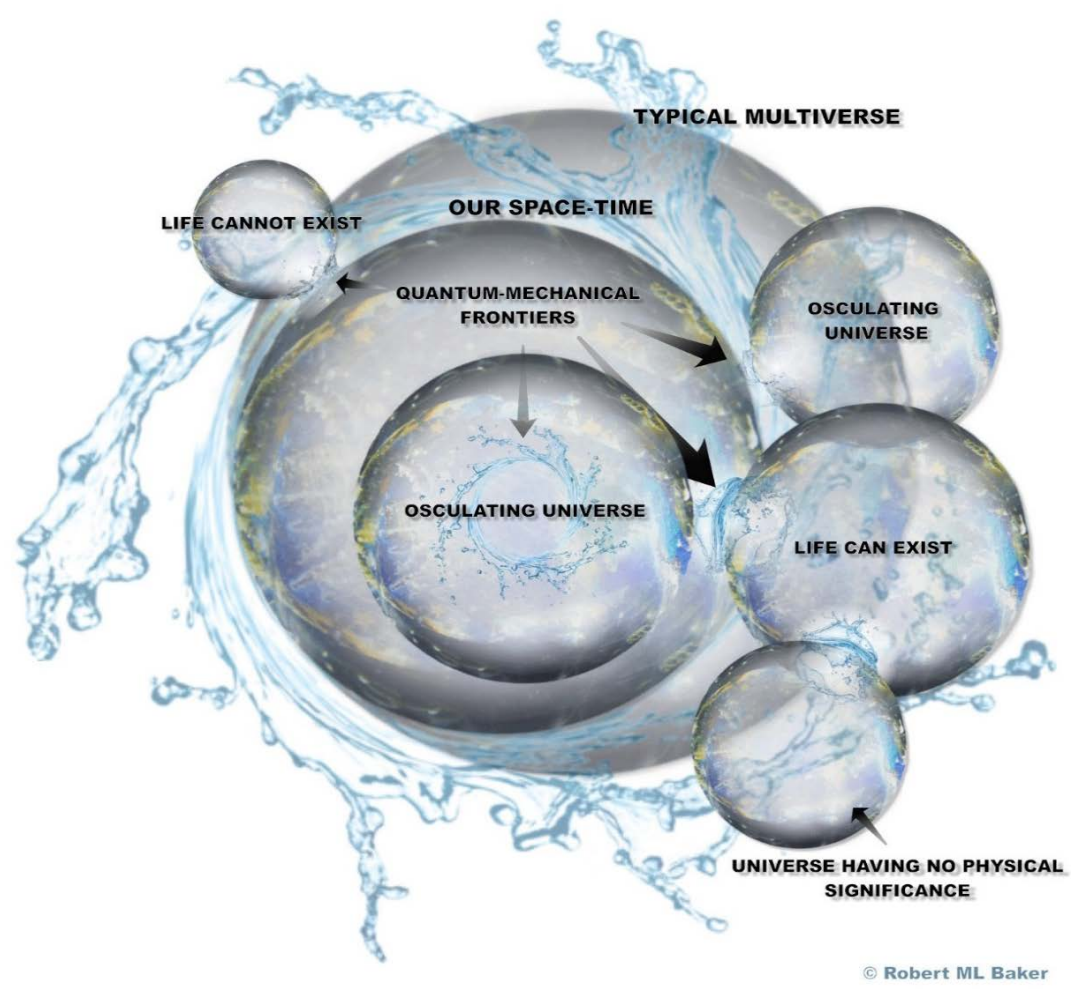

Figure 17. May not be the "Final" frontier for distant-future life forms in a Multiverse. From Figure 15 of [3] (Baker and Baker, 2021).

survive. Assuming there's no catastrophic events such as discussed in the next Section 4, which terminates the majority of life forms on the planet, we hypothesize Homo sapien Life form evolution will continue to select traits to improve survivability. As related to life forms on Earth, Glaciers grow for about 90,000 years and then, mainly due to unavoidable perturbations of the Earth's orbit about the Sun, take one or more 10,000 year periods to collapse or melt during the resulting unavoidable periods of considerable climate change such as global warming. [25] (Berger, 2021, Hays, Imbrie, Shackleton. 1976). Present life forms (humans, other animals. marine life, etc.) themselves, especially Humans, due to their current need to cultivate, transport, prepare, consume, digest and expel "nutritional residue" (sewage) create climate change. This is part of "...anthropogenic global climate change," According to [26] Michael Desai and his colleagues (Desai, 2019), “...the largest (climate change) probably being greenhouse gas produced by these world's food-production systems." There are adverse effects due to our human Life form's industrial activities and their use of contaminants to the atmosphere, lithosphere or, in general to the life form's neighborhood environment. The use of fossil fuels produces some atmospheric contamination and climate change, but their effect are smaller than the climate change caused by the World's food-production systems. As has happened for millions of years, temporary sea-level, atmospheric composition, etc. changes may 
result, but no major changes or adjustments in Homo sapien life form's structure or operation are expected to occur; at least not over next 20,000 to 30,000 years.

\subsection{Mind Boggling Progress and Adjustments}

The MEANS of Evolution for some life forms is expected to radically change in the near future. Homo sapiens as well as any and all life forms in our Universe will participate in the "Cyborg Revolution" Possibly the first major operational change in life forms, specifically Homo sapien life forms, is exhibited in Figure 4 and Figure 5, that is total mind control of mechanisms and equipment exterior to the life form. For example, turning on lights or an electric motor simply by thinking about the action. This progress, after perhaps thousands of years, would suggest the mind-boggling prospect: that, since they are no longer necessary, evolution would actually eliminate the need for external appendages such as hands and arms. Such appendages would be no longer be of competitive advantage. After tens of thousands or hundreds of thousands of years of non-use it would be reasonable to get rid of such appendages. "Just about everybody who thinks about trait evolution focuses on traits that are beneficial," writes first author [27] David Lahti (2009), a biologist at Queens College. "But few people think about traits (or body parts) that are useless, or that are becoming less useful over time will be no longer be of competitive advantage..." for survival. At this point, life forms such as human life forms and/or humanoid life forms (Figure 6), would be beginning to evolve into mainly "mental material" and commencing their evolution journey over perhaps millions or billions of years into a more secure (and survivable) spherical form. Such a Life form is fictionally described in Figure 3. We are now discussing time intervals in "Astronomer's time units" of millions and hundred billions of years. Evolution to a spherical form is easier to visualize by specifically, considering the humanoid $A i-D a$ shown in Figure 6. In her case the contraction of her parts and mental material to a spherical form could be imagined as a rather straight forward mechanical/electronic modification or rearrangement of her "parts".

What about other life forms existing at this evolutionary time in the "Terrestrial Part" of our Universe (home to the Homo sapien life forms) - the farm animals, pets, fish, birds, butterflies, mycelium, jungle beasts, bugs large and small, bad bacteria, viruses, fungi, et al? If they are unfit to survive or for artificial accelerated evolution, then they will NOT survive (our Universe is NOT a kind or gentle place). As long as they provide, comfort, amusement, service, etc. and do not "bother" the higher intellectual level life forms (in this case very advanced Homo sapiens, cyborgs, humanoids et al.), they will NOT evolve relate to or effect in any way the evolutionary path of the evolving advanced forms under consideration. They will, in fact, NOT be members of the elite "Survivor's Club"! Whose members are evolving advanced life forms (eventually including cyborgs and humanoids). The early life form Survivors essentially exhibited as lined up in the evolutionary parade at the top of Figure 15 will survive, and the rest will simply be neglected and left to perish. Like everything else in our Universe, all 
life forms have an opportunity to survive: "Survival of the Fittest" or "Law of the Jungle" Most probably do not become members of the Survivor's Club and as we suggest perish.

It is amazing how our brain and body can actually dramatically change in size and function as they might well do over time. Figure 18 actually shows how minibrains can "grow" crude eyes. This opens up the possibility that cyborg components need not always be electronic, but they could also be organic. Furthermore, the "design" of a life form could be accomplished by a system of controlled growth they cannot feel or love, for example. It's scary to think they will evolve and be able strategize even about things no human "put into them" but that could happen. We just don't know for sure if it will or when it will happen, possibly along a different evolutionary path. As mentioned in the Introduction, we restrict our study to "animals", but if, for example, a microscopic bacteria, fungus (for example a two-billion-year-old mycelium fungus, Helen Briggs, "World's oldest fungus raises evolution questions", BBC News, 25, April, 2017), somehow can develop an "intelligence" to "design", mentally remote control ALL its external functions and "install" some functional bacteria "part" and include or grow it in a new "model" of such a bacteriniod, then it might somehow participate in the Survivor's Club and eventually wind up on stellar orbit! Same goes for bunnyniods!

\subsection{Life form Sustenance Found on Stellar Orbits}

The next gigantic evolutionary step or steps, (each step now requiring hundreds of thousands, millions or perhaps billions of years in Astronomer's time units to accomplish), we suggest is that all life forms will evolve not to require "food" for survival. Rather life forms would find nourishment from the energy they collect directly from starlight. The most efficient way to accomplish that would be to install life form or Life form civilization on orbits about stars and/or galaxies that the life form and/or Life form civilizations orbit. (In the "Terrestrial Part" of our Universe, it is our star, the Sun.). The concept here is that nourishment or energy that the life forms require will evolve efficiently, not from the ancient practice of farming various crops, which collect energy from the Sun to grow, in order to provide the energy our life form's body requires after food preparation of the crops. NO, but energy directly from their star's "sunlight" to electrical energy (photovoltaic converted). The days of "hunter-gatherers" and "pastoralism and/or horticulturalism" will be completely over. Therefore a life form's ability to obtain energy directly from a star or stars will not result in any contaminants entering their "neighborhood" from food consumption, processing or waste disposal. A very "clean" Universe is anticipated. Essentially, we will be transformed, over millions if not billions of years, from a spherical blob-like embryo baby material of today, shown in Figure 19, to a spherical blob-like ball of embryonic mental material orbiting stars or galaxies shown in Figure 20 . 


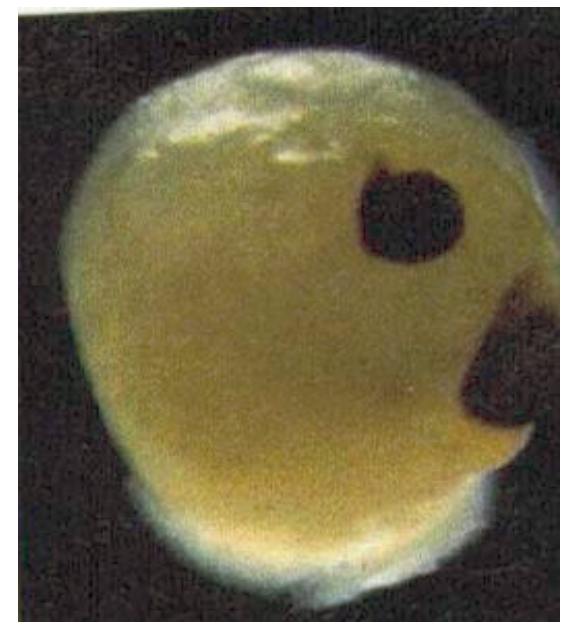

Figure 18. Two cup-shaped protrusions form rudimentary "eyes" in a lab-grown brain tissue. Picture from p 947, Science 373, Issue 6558, August 27, 2021.

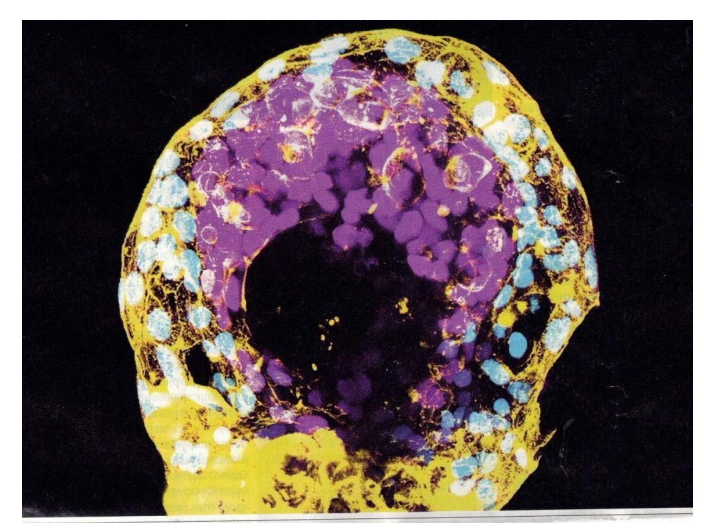

Figure 19. A human embryo of today, grown in the laboratory for 12 days [29] (Powell, (2021)).

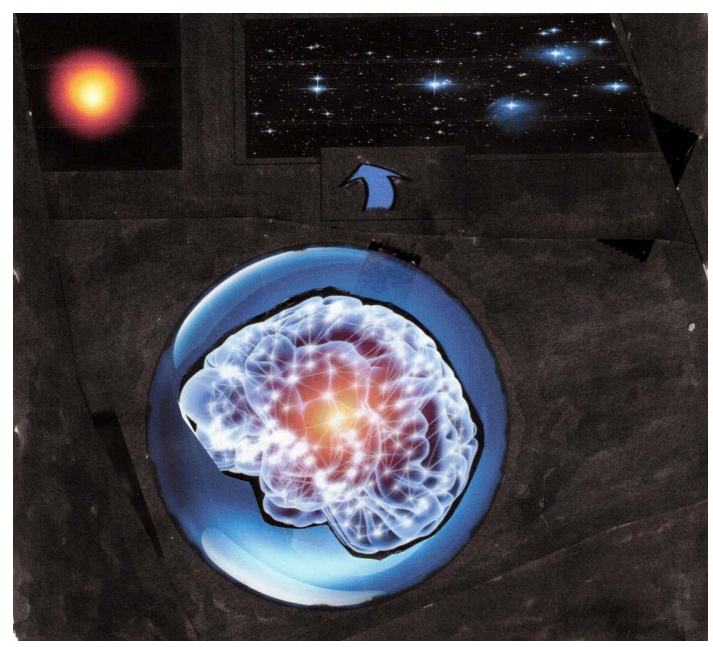

Figure 20. Artistic representation of the ultimate evolution of life-forms in our Universe to become living-thinking, mental material occupying spheres orbiting and nourished by a star or galaxy. 
It's hard to imagine that all other life forms will "eat" from starlight, become spheres and disappear off the Earth and other bastions of life in our Universe to orbit stars. And, also to fathom that the same evolution occurs for all other "Earths" in our Universe. We are considering change over millions or even billions of years of years from now. The evolutionary parade on the top part of Figure 15 is also very hard to imagine and sparked extreme controversy [28] (Larson, 2006): "How could we arise from monkeys much less fish?" But where did our fish fins go? And our Monkey tails-we know we had them since we still have tail bones? However, our evolution is ALL TRUE! Therefore it is not unreasonable to predict that in a few hundred thousand or million years we will become armored spheres, orbiting a star and feeding off its radiation -- Bon $A p$ petite!.

Actually, we will have "Accelerated Evolution" in which we predict "change" can be achieved by manipulation of parts of the eventual "humanoid" life forms populating our Universe, such as $\mathrm{Ai}-\mathrm{Da}$ (shown in Figure 6). Of course it is impossible to assert that ALL life forms in our Universe participate in the same evolutionary process, probably not in concert, but it is our best guess.

The period of time for the incubation, development and possible demise of a Life form civilization may be billions of years. As discussed in the "Rollout Theory of our Universe" [25] (Baker, 2020) and "Detection and Determination of the Variation of the Speed of Time" [31] (Baker, Baker and Li, 2021) because of the very high speed of time in our early Universe (extreme red shift stars), millions and billions of "years" as observed by astronomers today may appear to last only seconds today. Plenty of time for the formation and evolution of many Life form civilizations, especially if the speed of time increases since the beginning of our Universe.

As far as locomotion is concerned, a corollary would be the life form's ability to operate vehicles and/or devices to translocate the life form itself as suggested in the science-fiction movie from which Figure 3 was extracted. There also may be progress in a life form's ability to change, like a chameleon, its protective surface or shield from a shiny surface to reflect unwanted radiation like the Golden Tortoise beetle, to a black body to absorb energetic radiation required for power and "solar-sailing like" translocation. This is somewhat like the Klingon ships "cloaking" ability in the science-fiction television show Star Trek.

\subsection{Proposed Ultimate Specifications of the Life form of Our Species}

\subsubsection{Shape}

Life forms of our human species, and perhaps other non-human life forms, are expected to evolve having a shape to maximize volume, required in order to house their increased mental capabilities consisting of cognitive/micro-electronic or "living organic" material of the highest possible density and locomotion mechanisms, etc. and minimize surface area or their target area they present to any and all predators for protection? Since it is the geometric figure exhibiting the 
largest volume to area ratio is a sphere its shape would become spherical.

\subsubsection{Weight}

It is anticipated that the fit, survivable life forms of our species, and perhaps other non-human life forms, would locate themselves in the weightless free-fall of outer space. Therefore, weight would be of no consequence. Their mass might be minimized' for enhanced mobility and in order to house their increased mental capabilities consisting of cognitive/microelectronic material of the highest possible density; and a low-mass propulsive mechanism. Their actual size or dimensions (e. g., diameter since spherical) would be defined by their maximum volume. Although their volume might be considered to be unconstrained, since they are assumed to become on orbit about a star or stars (e.g., orbiting a galaxy), if they present too large of an area, then danger from debris, radiation, predators or other dangers might be increased as their exposed area is increased. Therefore some compromise would be struck.

\subsubsection{Locomotion}

Since it is anticipated that the fit life forms would locate themselves in the weightless free-fall of outer space, orbiting a star or galaxy, they would not require locomotion, except a small amount for orbit-keeping, or mobility for harvesting or collecting food or energy. Nevertheless, locomotion would be required in order for the Life form to avoid predators and other dangers. Therefore, they would require some propulsive mechanism such as "solar sailing", electrostatic propulsion or be equipped in order to scoop up materials from the space in their immediate vicinity and electrically accelerating it for propulsion.

\section{Demise}

("So many ways, so much time" Bobbie Baker, 1936, the "Kiddish Country" and Battle Cry, January/February 2019 issue,)

Albert Einstein is reported to have stated: "Imagination is more important than knowledge. For knowledge is limited to all we now know and understand, while imagination embraces the entire world, and all there ever will be to know and understand."

Following that edict, we will utilize the imagination from Science-Fiction movies to suggest possible situations resulting in the demise of a Life form civilization:

Very Little Bugs ("War of the Worlds," 2005 ["The smallest among us (microbes) could kill off their entire Martian civilization!”]) (“Andromeda Strain” 1971 [Virulent pandemic, e.g., COVID-9999999, from outer space.])

Very Big Bugs (“Them," 1954 [Giant Ants attack], "Godzilla," 1998)

Lethal Orbital Collision ("When Worlds Collide," 1951,)

Lethal Encounter ("Alien," 1979 [Deadly monsters unleased on other lifeform civilizations. By the way, probably it was the author of this horror movie, Dan O'Bannon, who imaginatively reminds us that cyborgs need not always be 
filled with electronic components, but that organic components \{like those in the Movie's character "Ash"\} might also do nicely.])

Mental Self Destruction ("Forbidden Planet," 1956 [Mind control of a nightmare monster killed the Krell Life form civilization.])

Extinguishing of Mother Star/Galaxy ("Forbidden Planet," 1956 [Destruction of the central "Mother" planet at Movie's end]) [A star with a mass like our Sun can continue fusing hydrogen for about 10 billion years. On the other hand, if the star, which a more mature spherical Life form has chosen to orbit is very small, with a mass only a tenth that of our Sun, it can keep fusing hydrogen for more than the 100 billion years during the early Universe.]

Overtaken by Cybernetic Devices ("Rise of the Machines, Terminator 3," 2010), ("Westworld," 1973 [Amusement park androids that malfunction and begin killing visitors, could kill off any Life form civilization that enjoys amusement.])

Police, "Robocop," 1987 ("The Day the Earth Stood Still," 1951 [Powerful robot Gort, policing the Universe and destroying ANY "dangerous" Life form civilization it finds.])

Politics ("Survival of the fittest" scientifically determined law \{Spencer, 1852; Darwin, 1859\} unavoidably replaced by an attractive "Welfare State," which has a fatal attraction for and enslaves the electorate by providing "free" goods and services in return for maintaining, by election (tyranny of the majority), a huge and powerful central government. A powerful government that unavoidably and ultimately is attracted to and directed by a resourceful, nefarious leader (e.g., Mao Tse Tung, Maduro, Pol Pot, Hitler, Peron, Stalin, Mussolini, Castro, et al. leading to the demise of a Life form civilization)

Sports ("Predator," 1987 [Encounter with a creature that has "fun" hunting and killing an entire Life form civilization]), "Hunger Games." 2012 [Promotes the "fun" of killing off a Life form civilization's "people"], "War Games," 1983 [Computer takes over a ballistic-missile system and thinks it's all just a "game" to destroy countries including the "tit-tat toe" game, which the computer finds cannot be won.])

Artificial Intelligence. Elon Musk in the 2018 documentary about artificial intelligence, Do You Trust This Computer? "If AI has a goal and humanity just happens to come in the way, it will destroy humanity as a matter of course without even thinking about it, no hard feelings." Musk warns that the creation of superintelligence could lead to an "immortal dictator." That would end a civilization as we know it

Nutrition ("Soylent Green," 1973 ["People live in the streets and line up for their rations of water and Soylent Green. That's a high-protein foodstuff allegedly made from plankton cultivated in the seas. But actually from the bodies of people who die" leading to a demise of a Life form civilization])

Dream "Machines" (" $13^{\text {th }}$ floor," 1999 ["A newly completed virtual reality simulation (VR) of 1937 Los Angeles discloses some extraordinary situations."]) (The "Matrix", 1999 [In which intelligent machines have been created to distract 
humans while using their bodies as an energy source. When computer programmer Thomas Anderson uncovers the truth, he is drawn into a rebellion against the machines along with other Life form civilizations who have been "freed" from the Matrix. But if the programmer fails, then a demise of a lifeform civilization would ensue.)

Slow degradation of a life form (Not truly a DEMISE, but gradually withering away to a life form "nothingness." Similar to the famous comment by General Douglas MacArthur: “Old Soldiers never die-they just fade away!”).

\section{Suicide or lack of will to go on.}

\section{Conclusions}

It is easier to conclude a simple sequence for Life form Evolution rather than a precise time-ordered sequence. For all Life forms in our Universe, be they amoebas, fungus, bugs, or bunnies, human or non-human humanoids, the simple sequence in time we suggest is:

1) Complete Life form's conversion to a cyborg and/or (for Homo-sapiens)

Humanoid configuration as being the very fittest life form since it would be both repairable and improvable by other life forms.

2) Inclusion in brains exhibiting a communications capability: e.g., brain to brain, brain to machine, brain to HFGW transceiver, etc. communication capability. Thus, the supporting electronic circuits will need to be very close together and electronic "brain" components of minimum volume.

3) Developed and implemented artificial education function.

4) Elimination of the need for external appendages such as hands, arms and legs by cognitive control of locomotion and all external devices and mechanisms.

5) Development and fabrication of minimum target or surface area shields for protection of life form's Predators.

6) Optimum (because of 2) and 5) constraints) for all Life forms to be spherical in shape-no other solid-geometrical shape will be as fit.

7) Direct conversion of stellar radiation ENERGY to the energy needed for the life form to function.

8) Artificial, Accelerated Evolution would involve the replacement or repair of their "parts" especially if they were largely composed of electronic components as we predict for human life forms in the future.

9) Direct conversion of stellar radiation energy to the energy needed for the life form to function.

10) Life form's ability to operate vehicles and/or devices to translocate the life form itself by means of an appropriate propulsion to adjust stellar orbits-artificial planets.

11) Selection and translocation to an appropriate stellar-orbital locations achieved.

BUT what will the Life form do for the justification for its Existence and for Amusement? 
a) Imagination, leading to curiously, leading to understanding, leading to:

b) Creativity and the justification for its existence. For example, discovering and analyzing in detail our human life form would certainly justify "their" existence!

c) Amusement: for example:

i) Sports (e.g., Bowling),

ii) Games,

iii) Exploration,

iv) Hobbies,

v) Art,

vi) Movies, etc. and, of course,

vii) SEX (returning to the science-fiction movie's aspect of imagination, we suggest the "Orgasmatron" from Woody Allen's movie "Sleeper", 1973).

\section{MAIN CONCLUSION ${ }^{4}$ :}

Spherical form: As outlined in Section 5, the only reasonable ultimate design that the Life forms in our Universe will take is the one capable of adapting to environmental change by repair and design change by itself or by other life forms. Therefore, the only shape having a minimum volume (exhibiting the minimum inter component distances) and the smallest target area (for protection) is, by the laws of Solid Geometry and Physics, a sphere. Possibly the shape of a liquid drop of any mass or density in gravity-free space is a model. Also we agree with Itai Yanai's and Martin J Lercher's conclusion [33] from Gee's Book: A (Very) Short History of Life on Earth, that "...our Earth will be uninhabitable to even the hardiest organisms, spelling the final doom for Earth-evolved-life unless, perhaps, some earthlings manage to escape into space first." We agree, but we believe that the earthling will probably escape and inhabit spheres orbiting stars and galaxies!

Motivation: Other active life forms in our Universe are probably more curious about us (about our human life form) than we are about theirs. That curiosity and resulting creativity would serve to encourage and justify "their" existence! (Consider the curiosity of the little extraterrestrial botanist in the fanciful 1982 Science-fiction movie "ET".) Also "they" would have probably evolved not to just a spherical shape composed of mind or "thinking" and "communicating" matter orbiting a star (Figure 20), but to an enormously greater level of intelligence, imagination 1 and observational capability than have we! Therefore, let's reformulate our search for extraterrestrial life from looking for their signals to striking up a conversation by greatly enhancing our ability to propagate a "Hello There. How Are You?" Signal. But Beware: please see [3] “Application of HighFrequency Gravitational Waves to the Cataclysmic Event of Our First Encounter with Intelligent Extraterrestrial Beings".

\section{Acknowledgements}

The authors express their appreciation for the editing and most helpful com-

${ }^{4}$ Will the ultimate life form be male or female or both? The authors remain undecided! 
ments provided by Mellissa King, MBA. Senior Fellow Advocacy \& Public Affairs, regenerative medicine foundation, Jan 2021-present, Chief Operating Officer, brain window, INC, Medical device company and Jeremy Horne, philosopher extraordinary.

\section{Conflicts of Interest}

The authors declare no conflicts of interest regarding the publication of this paper.

\section{References}

[1] Darwin, C. (1859) The Origin of the Species. Digital Edition, Goldstein, London.

[2] Spencer, H. (1852) A Theory of Population (Anonymous). The Hayworth Papers, March 20.

[3] Baker, Jr., Robert, M.L. and Baker, B.S. (2016) Journal of Applied Mathematics and Physics, 4, 110-129. https://doi.org/10.4236/jamp.2016.41015

[4] He, B., Yuan, H., Meng, J. and Gao, S. (2020) Neural Engineering. 3rd Edition, Springer Nature, Berlin.

[5] Jones, L. (2021) What Will Humans Look like in a Million Years. https://www.bbcearth.com/news/what-will-humans-look-like-in-a-million-years

[6] Vetere, G., Tran, L.M., Moberg, S., Steadman, P.E., Restivo, L., Morrison, F.G., Ressler, K.J., Josselyn, S.A. and Frankland, P.W. (2019) Nature Neuroscience, 6, 933-940. https://doi.org/10.1038/s41593-019-0389-0

[7] Service, R.F. (2013) Science, 340, 1162-1165. https://doi.org/10.1126/science.340.6137.1162

[8] Veloso, M. (2015) Nature, 521, 415-418. https://doi.org/10.1038/521415a

[9] Greene, B. (2017) Year Million. Life Science Newsletter, May 15. https://www.livescience.com/59115-year-million-series-explores-future-of-humanit y.html

[10] Denny, C. (2020) Modifications of a Mouse's, Brain. Boston College Magazine, Spring.

[11] Willett, F.R., Avansino, D.T., Hochberg, et al. (2021) Nature, 593, 249-254. https://doi.org/10.1038/s41586-021-03506-2

[12] Baker, Jr. and Robert, M.L. (2013) About Face, Economic Round Table, the California Club, Los Angeles. PowerPoint Presentation, May 2.

[13] Noy, A. (2011) Advanced Materials, 23, 807-822.

[14] Gulati, T., Won, S.J., Ramanathan, D.S., Wong, C.C., Bodepudi, A., Swanson, R.A. and Ganguly, K. (2015) The Journal of Neuroscience, 35, 8653-8661.

https://doi.org/10.1523/JNEUROSCI.5007-14.2015

[15] Machens, C.K. (2012) Science, 338, 1156-1157. https://doi.org/10.1126/science.1231865

[16] Mannoor, M.S., Jiang, Z., James, T., Kong, Y.L., Malatesta, K.A., Soboyejo, W.O., Verma, N., Gracias, D.H. and McAlpine, M.C. (2013) Nano Letters, 13, 2634-2639. https://doi.org/10.1021/nl4007744

[17] Marx, V. (2015) Nature, 522, 373-377. https://doi.org/10.1038/522373a

[18] Hirschberg, J. and Manning, C.D. (2015) Science, 349, 261-266.

https://doi.org/10.1126/science.aaa8685 
[19] Chappell, B. (2021) The Journal of Clinical Investigation, 131, e1511331.

[20] Power, S.A. (2014) Science, 345, 262. https://doi.org/10.1126/science.1255866

[21] Grey, R. (2016) Could We Soon “Speak” Telepathically? Mind-Reading Computer Deciphers Words from Brainwaves before They Are Spoken. Daily Mail. https://www.dailymail.co.uk/sciencetech/article-3386875/Could-soon-speak-telepat hically-Mind-reading-computer-deciphers-words-brainwaves-spoken.html

[22] Baker, Jr. and Robert, M.L. (2017) Gravitational Waves, the World of Tomorrow, a Primer. 3rd Printing, Infinity Publishing, West Conshohocken.

[23] Haldane, J.B.S. (1929) The Rationalist Annual, 148, 3-10.

[24] Vilenchik, L. and Vilenchik, M. (2019) Journal of High Energy Physics, Gravitation and Cosmology, 5, 884-898. https://doi.org/10.4236/jhepgc.2019.53044

[25] Berger, A. (2021) Climate of the Past, 17, 1727-1733. https://doi.org/10.5194/cp-17-1727-2021

[26] Desai, M. (2019) Nature, 575, 275.

[27] Lahti, D.C., Johnson, N.A., et al. (2009) Trends in Ecology and Evolution (TREE), 24, 487-496. https://doi.org/10.1016/j.tree.2009.03.010

[28] Larson, E.J. (2006) Summer of the Gods. Basic Books, New York.

[29] Powell, K. (2021) Nature, 597, 22-24. https://doi.org/10.1038/d41586-021-02343-7

[30] Baker, Jr. and Robert, M.L. (2020) Journal of High Energy Physics, Gravitation and Cosmology, 6, 609-622. https://www.scirp.org/journal/jhepgc

[31] Baker, Jr., Robert, M.L., Baker, B.S. and Li, F.Y. (2021) Journal of Modern Physics, 12, 761-780. https://doi.org/10.4236/jmp.2021.126049

[32] Blenkinsopp, R., Young, G.W., Milne, H., et al. (2020) Proceedings of the ACM on Human-Computer Interaction, 4, Article No. 81.

[33] Yanal, I. and Lercher, M.J. (2021) Science, 374, 828. https://doi.org/10.1126/science.abm0121 